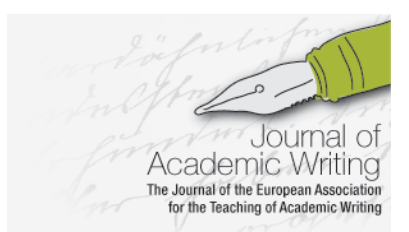

Journal of Academic Writing

Vol. 6 No 1 Autumn 2016, pages 108-121 http://dx.doi.org/10.18552/joaw.v6i1.260

\title{
Pedagogical Design Promoting Writing Productivity on the Doctoral Level - a Case Study from Finland
}

\author{
Pia Helena Lappalainen \\ Aalto University, Finland
}

\begin{abstract}
Publication productivity constitutes a key measure of institutional and researcher performance, determining success in university rankings and academic career development. To promote such productivity, Aalto University launched the Writing Doctoral Research course for engineers. To build a domain-specific course for doctoral candidates, their needs were examined quantitatively $(n=325)$ and qualitatively $(n=74)$. The aim was to identify pedagogy for raising the quality of publications and expediting doctoral degree completion.
\end{abstract}

These investigations showed that 1) in the absence of sufficient supervision, engineers require more support in writing-related mental processes, 2) the mechanics of writing needs to promote argumentativity, 3) researchers lack precision when describing their research aims, 4) articulation of causality in data commentary requires more accuracy, and 5) instruments must be provided for writer self-correction.

Instead of taking the lexicogrammar approach, the course was designed in a way that aligned with the principles of enculturation, assisting researchers in scientific positioning and socialization into their fields. Such an approach emphasizes reporting and structural conventions in engineering and the field-specific academic style.

\section{Introduction}

University reforms and restructuring can presently be recognized as a larger, international trend, keen on identifying pedagogy for disseminating working life skills and securing graduates' employability (Manathunga 2012). On the postgraduate level, publication productivity is treated with a growing note of urgency, constituting the key indicator of institutional and researcher performance and determining success in university rankings and academic career progress (Cotterall 2011 and Kamler 2008).

Doctoral degree programmes are struggling universally to pursue high-impact content and form. The challenges stem largely from the research writing process, and are associated, in particular, with the related policy, theory and pedagogy (Aitchison and Lee 2006). To make the matter worse, supervisors are often second-language speakers of English, which undermines their ability to identify doctoral candidates' competence gaps in writing (Allison et al. 1998). In addition, institutional inability to consider such globally posed researcher requirements as emotional labour sets further demands on the faculty (Aitchison and Mowbray 2013). A growing body of literature (Paltridge 1997) and innovative university-level policies have subsequently attempted to provide interventions that expedite doctoral degree completion and raise the quality of research outputs (Aitchison and Lee 2006). 
Development endeavours are particularly pivotal for such new universities as Aalto in Finland, which need to find a niche and establish their position among traditional operators in the fiercely competitive global arena. As a new opening, a higher-level decision was made in 2011 to launch a writing course on the doctoral level, which had never before been on offer. However, despite the policy shift being well-intended, the pedagogical development measures dictated top-down at Aalto University induced certain risks. The language centre pedagogues traditionally have a master's degree in the humanities, meaning that they both had to design courses for fields they were unqualified for (Stapp 1998) and were to create offerings for a level that they had not completed a degree in themselves, implying the necessity to acquire understanding of research methodologies, instruments and domain-specific content. As a quick-fix measure, the responsibility for the course design was allocated to a lecturer who had a degree in both science and English philology.

Moreover, on the doctoral level, the student audiences were extremely diverse, with only 30 $35 \%$ coming from Finland. To further add to the heterogeneity of audience make-up, Aalto was founded as a merger of three universities: School of Economics, Schools of Arts and University of Technology. Even though engineers make up $70 \%$ of the student mass, the probability of artists or economists attending doctoral writing courses had to be taken into account.

As is logical with new content and course design, pedagogical development ought to rely on research evidence to avoid any undesired effects on classroom practices (McAlpine and Amundsen 2012) but there was neither time nor resources for needs analyses or thorough material design. On the Bachelor's and Master's levels, the language centre applied school book examples and writing instructions from social sciences, but on the post-graduate level, the material needed to be authentic. Engineering texts are known to adopt certain distinct linguistic practices e.g. in terms of the use of voices and verb tenses, which forced the teachers to appreciate the special disciplinary conventions in engineering (Douglas 2015).

As the researcher products would be assessed in real-life journal blind reviews, the fact that the nuances of academic writing vary by discipline urged the teachers to reconsider their pedagogical approach (Brooks-Gillies et al. 2015). Student motivation also posed a concern: in technical fields, writing and rhetorics are often considered subsidiary to technical development, which explains why the writing process is typically regarded as laborious and less motivating compared to design and empirical data collection and analysis. Some researchers find documenting a phase that disrupts the flow from empirical analysis in the engineering lab to doctoral degree completion (Aitchison and Mowbray 2013).

This study analyses the challenges perceived by doctoral students in research writing, pursuing pedagogy for a course that, upon initiation of the present analysis, had no previous materials or methodology to rely on. The study serves two aims: first, it sheds light on doctoral candidates' needs in terms of research writing. The needs analysis is based on a quantitative survey of a sample of 325 doctoral candidates at Aalto University and a qualitative analysis of 74 abstracts or introductions to journal articles or dissertations. Second, based on the two analyses, this study proposes emphases for doctoral programs in engineering to support the publication process. The ultimate objective is to facilitate the writing process and to raise publication quality by proposing concrete instruments and priorities for doctoral degree programs.

\section{New emphases in Aalto University doctoral programs}

To support doctoral students in the extremely competitive publishing culture, Aalto University launched the course Writing Doctoral Research (WDR) in 2011. The aim was to provide education in scientific writing, which at the University in question was earlier dismissed as a mere cosmetic component of lesser importance in the overall research process compared to lab experiments, technological innovations or empirical designs. The fierce selectivity of academic journals, however, has gradually made the University policy makers more favourable towards writing courses, clinics and online aids, and presently language is valued as an element leveraging the overall research quality. 
The endeavour taken up with the course in question was immense, as it was to ambitiously meet a variety of student needs while responding to policy shifts. Among individually driven requirements, earlier literature has identified diverse topics of mental nature, e.g., learner styles (Cagiltay 2008), learning outcomes (King 2009), enculturation (Yu 1998), procrastination (Murray 2006), and student self-concept (Aitchison and Mowbray 2013), and such studies were adopted as a platform for the course design. At the same time, the faculty understood that the course design needed to be informed by more concrete understanding of student needs on the doctoral level.

Academic writing is often viewed as a competence that can be taught through a set of generic skills separate from content and context (Paltridge et al. 2012). This, however, underestimates the complexity of doctoral writing, in which the field-related conventions, unique discourses and field-specific research traditions strongly dictate and characterize the writing style and structure. Unfortunately, the engineering schools at the University have been lacking in writing guides and stylebooks that would draw on examples and best practices from authentic engineering texts. Generally the staff have relied on prior research evidencing the need to teach data commentary, general-specific patterns, summaries and problem-solution texts, but unfortunately many of these guidelines have been created for social sciences, which has caused a discrepancy with engineering journal requirements. Furthermore, writing instructions have only rarely provided support for dissertations, which pose entirely different types of challenges compared to smaller-scale writing tasks on the undergraduate level (Allison et al. 1998).

Yet another consideration when redesigning doctoral curriculum in engineering is the misconception voiced frequently by students of technology in writing clinic appointments that writing that flows smoothly is driven by inspiration and it happens when it happens. Proponents of writing as an inherent talent overlook that fact that writing is a skill that can be learned, developed and taught (Murray 2006). It is, in fact, possible to develop competence and confidence in writing, turning inspiration redundant and aiding researchers who suffer from a blank page syndrome. This reduces pressure especially in performative cultures such as universities that feature emphasis on productivity, with publications as the only measure that counts. As the writer's block is most often caused by negative self-talk stemming from perfectionism and feelings of inadequacy, attention should be directed to students' mental processes, especially self-concept and self-leadership. These emotional reactions and struggles need to be attended to in doctoral programs (Aitchison and Mowbray 2013).

Other, more practical, barriers naturally include competing demands for researcher time and lack of support from the department (McLeod et al. 2012). Even though academic achievement has generally been associated with high motivation, good time management and effective study skills (Cassidy 2012), students on the doctoral level still require concrete supervision. In the absence of sufficient faculty resources, lack of instruction from the supervising professor poses a major concern for many doctoral candidates, and therefore other sources of assistance and moral support should be sought.

As one such channel, the University decided to invest in pedagogy facilitating peer critique. Caffarella et al. (2000) claim that the learning process can with little effort be facilitated by peer and professor feedback, helping novice writers to both write and think like scholars. Their findings show that scholarly writing can most effectively be supported by personalized face-to-face feedback and iterative or ongoing critique. However, it is recognized that receiving feedback can be highly emotional and even frustrating and therefore students need help in understanding the benefits and purposes of critiquing and also in learning how to give and receive useful feedback. Feedback requires reviewers with extensive experience as reviewers for academic journals and who have also received critiques of their own writing. Furthermore, it should be emphasized that giving and receiving feedback across disciplines is advantageous (McLeod et al. 2012), despite engineers typically valuing highly the deep, domain-specific expertise of others from their own specific technical field. In fact, it may even be easier for an outsider to assess how well the author manages to sustain his arguments over longer passages of writing (Allison et al. 1998) when they read less in between the lines. 
This justifies the organization of the WDR course in question into mixed student groups comprising researchers from all Aalto Schools.

In addition to the above challenges, there are also more substantive and fundamental learning needs involved in scholarly writing. Students struggle in writing effectively in a way that follows a prescribed, domain-specific format and applies correct terminology. Their writing strategies also require attention in doctoral courses; despite efforts to plan writing, there is no evidence that the think-then-write order has more utility than the think-while-youwrite strategies. Therefore, writing education should add iteration and rewriting of text to students' writing repertoires, instead of only accentuating linear progression from ideation to actual writing (Caffarella et al. 2000).

Writing poses difficulties also grammatically, as most students in the WDR course are speakers of English as a second language. Although cultural diversity in the classroom is fostered as advantageous for the skilling of global citizens, the international audience struggles with punctuation, articles, tense and structuring, which constitute problems identified also by earlier literature (Strauss 2012).

\section{Understanding student needs}

When designing a new course from scratch, it was of the essence to collect student insights and feedback to ensure the provision of relevant education that meets doctoral candidates' needs. As a broader pedagogic trend in engineering, attention has gradually shifted from instructional lecturing to authentic, activating, reflective and problem-based exercises, allowing students to bridge the gap between theory and practice (Borges et al. 2009 and Kreps and Lederman 1985). However, implementing such pedagogy in practice and ensuring provision of hands-on, relevant and concrete classroom activities aiding research writing necessitated a student needs survey among doctoral candidates.

\section{Study method}

When the WDR course was launched in 2011, the course development was in its infancy, with the contents and materials based on courses offered at the Master's level and therefore requiring major revising. A preliminary, qualitative survey was directed, upon course start, to the first two groups attending the WDR course, both with 15 attendees. This needs analysis allowed the 30 attendees to elaborate freely and anonymously on topics conceived as significant for course design, by means of two open questions: 1) what are your immediate learning needs and 2) what are your long-term learning needs.

This first survey aimed to reveal directions for immediate course design. The themes that surfaced in the open-ended questions were then moulded into 15 questionnaire items for the second, quantitative survey $(n=325)$ that analysed students' learning needs in more detail. This second survey was complemented with a qualitative analysis of student texts $(n=74)$.

In Finland, engineers mostly write article-based dissertations, with their individual articles having been submitted to and accepted by international journals. The main challenge for them lies in the synthesis introduction that compiles the key content of all the independent studies into the first chapter of their thesis, which is why the course focused on writing an effective introduction, and the qualitative analysis therefore also centred on this section.

After the first two courses, a course feedback form $(n=30)$ surveyed through open-ended questions 1) what the students had learned, 2) what was not covered that they would have needed, 3) what they liked about the course, and 4) what they did not like about the course.

Content analysis of their responses in the two preliminary surveys revealed 15 main themes that, when grouped thematically, formed three main areas pertinent to writing academic publications: content creation or ideation, the actual production of text, and feedback reception. The emotive labour involved in critique emerged as a surprise in the highly analytical, rational engineering culture in Finland, where learner moods, sentiments and well- 
being have only recently begun to be addressed (Lappalainen 2012). However, the finding is in alignment with prior literature indicating that scholarly writing involves investment in content, process, and critique (Murray 2006).

In terms of possible course foci, this suggests that scholarly writing as an educational and personal development process involves three components: building content, managing the writing process and dealing with critique. Content refers to the ability to argue on the grounds of literature or empirical evidence. Process acknowledges scholarly writing as an iterative effort of rewriting. Finally, critique denotes skills in feedback reception and provision during the drafting and rewriting phases (Murray 2006). Feedback that lacks quality and substance or is contradictory may cause anxiety or frustration, known to erode learners' mental abilities and hamper the ability to process information analytically (Goleman et al. 1998).

The 15 themes that surfaced from the preliminary survey were adopted for a quantitative survey ( $n=325)$ using a Likert scale from 1 (not very important) to 5 (very important). As the 15 themes were broad, unspecific and subjective self-reports, a qualitative examination $\left(n=74^{1}\right)$ of student texts (abstracts and introductions to journal articles or dissertations) was needed to complement and specify the quantitative results. Figure 1 outlines the overall research design.

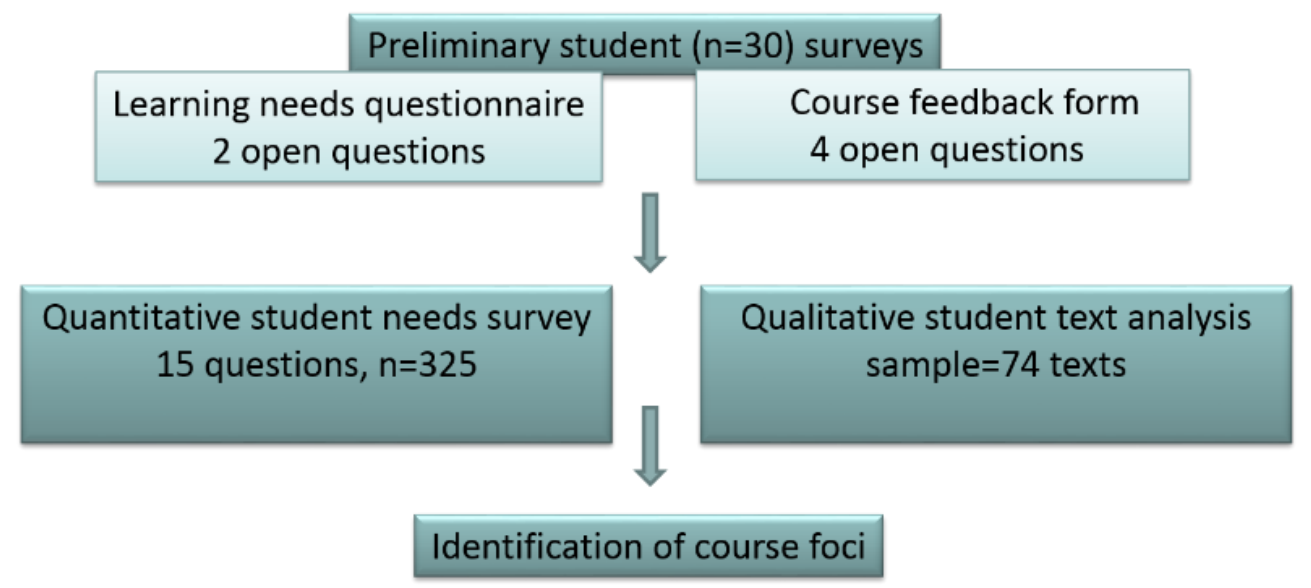

Figure 1. The overall research design.

\section{Results}

The two preliminary surveys (1. open-ended questions regarding learning needs, 2 . feedback form) yielded student perceptions of their competence gaps. Table 1 lists the 15 themes that surfaced from the preliminary student surveys.

\footnotetext{
1 At the time of the writing of this article, 74 students had granted the author with the permission to use their texts for public analysis.
} 
Table 1. The quantitative survey items as grouped under the thematic areas.

\begin{tabular}{|lll|}
\hline Process component & Item number & Question item \\
\hline Creating content & 1 & Generating ideas \\
& 2 & Arguing for my ideas \\
& 3 & Finding credible sources \\
& 4 & Expressing my views with precision \\
\hline Writing & 5 & Getting started with writing \\
& 6 & Organizing sentences into coherent sections \\
& 7 & Organizing ideas into logical sentences \\
& 8 & Mastering grammar \\
& 9 & Finding appropriate terminology \\
& 10 & Polishing my style \\
& 11 & Detecting my own mistakes \\
\hline Receiving feedback & 12 & Understanding counter-arguments \\
& 13 & Accepting constructive criticism \\
& 14 & Not getting too emotional \\
& 15 & Deciding what to implement \\
\hline
\end{tabular}

Altogether 325 doctoral candidates responded to the survey in 2011-2015 prior to attending the course. Table 2 lists the average scores received for the 15 question items and reveals that in the writing process, content creation and feedback reception pose fewer problems than text formulation.

Table 2. The averages, standard deviations and medians for the question items.

\begin{tabular}{|l|l|l|l|l|l|}
\hline & Question item & Avr & Md & $\begin{array}{l}\text { St } \\
\text { Dev }\end{array}$ & \\
\hline 1 & Detecting my own mistakes & 3.81 & 4 & 0.88 & writing \\
\hline 2 & Polishing my style & 3.73 & 4 & 0.85 & writing \\
\hline 3 & Expressing my views with precision & 3.65 & 4 & 0.80 & writing \\
\hline 4 & Getting started with writing & 3.39 & 3 & 1.01 & writing \\
\hline 5 & Mastering grammar & 3.36 & 3 & 0.99 & writing \\
\hline 6 & Arguing for my ideas & 3.33 & 3 & 0.90 & content \\
\hline 7 & Deciding what to implement & 3.31 & 3 & 0.81 & content \\
\hline 8 & Organizing sentences & 3.30 & 3 & 0.87 & writing \\
\hline 9 & Organizing ideas & 3.27 & 3 & 0.90 & writing \\
\hline 10 & Finding appropriate terminology & 3.25 & 3 & 0.89 & writing \\
\hline 11 & Finding credible sources & 3.01 & 3 & 0.93 & feedback \\
\hline 12 & Generating ideas & 2.89 & 3 & 0.99 & feedback \\
\hline 13 & Understanding counter-arguments & 2.79 & 3 & 0.84 & feedback \\
\hline 14 & Not getting too emotional & 2.73 & 3 & 1.06 & feedback \\
\hline 15 & Accepting constructive criticism & 2.57 & 3 & 0.97 & feedback \\
\hline
\end{tabular}

The survey results direct the pedagogic focus to elements closely linked to language features and writing strategies supporting formal and scholarly text formulation. The top three items, Detecting my own mistakes, Polishing my style and Expressing my views with precision, also showed a comparatively low standard deviation, meaning that they were found challenging 
unanimously by the sample. Further, the top three items received, logically, higher medians than the rest of the items.

Due to the small sample size and unscientific labelling of the question items following student wording, the figures in table 2 have to be regarded as suggestive. However, they provide indication of the average needs of the majority and thereby suggest priorities for doctoral writing course design. Further scrutiny was called for to acquire an objective teacher perception of the students' learning needs. This qualitative investigation complemented the previous, quantitative analysis and was necessary for two purposes:

1) to acquire a more objective understanding of student needs, and

2) to obtain a database of authentic student samples exemplifying common mistakes.

Altogether 74 doctoral student abstracts or introductions were examined as background material for the course design. The selected texts were chosen on the basis of student permissions to publish their texts in a public forum. Understandably, not all researchers wanted to publicly share their samples before publishing.

The text samples were examined following discourse analysis to identify any recurring patterns extending across sentences and paragraphs or smaller-scale elements, for example, words and phrases (Charles et al. 2009). Specific disciplinary conventions need to be examined to identify domain-typical patterns, contextualize them, and create a mental framework helping comprehend the disciplinary expectations (Douglas 2015).

The analysis supplemented the results from the quantitative survey by supplying concrete evidence backing up student perceptions in the quantitative survey. The following section details the key focus areas proposed by the quantitative survey and complements it with findings from the qualitative text analysis. Finally, it concludes with additional findings that surfaced from the text analysis.

\section{Analysis of findings and implications for the Writing Doctoral Research course}

In general, the composition of text not only involves micro-level mechanics of writing but also deeper, macro-level strategies supporting argumentation and positioning and enhancing persuasion and credibility targets (Hacker 1999), and both these levels were addressed in the quantitative survey and backed up by evidence emerging from the qualitative investigation. The section below takes a closer look at the top five items in the ranking.

\section{Detecting my own mistakes}

Authors become blind to their own writing. Even in their last home assignment, students made mistakes with issues that had been covered in class. This signals that despite growing awareness of the appropriate expressions, it is challenging to detect incorrect output in one's own text.

In their personal feedback sessions, the students expressed frustration with the mistakes they had made while articulating awareness of the correct expressions. They recognized the difficulty in adopting new writing strategies and approaches, especially in terms of readability and audience impact. More precisely, weaknesses in usability materialized as incoherence, complex sentence structures, clumsy information ordering and overuse of heavy passives. However, they also expressed relief at having become apt in detecting errors in peer papers, perceiving this as a sign of growing awareness.

As a remedy, three strategies could be proposed:

A. Putting the paper away for a few days may support reflective practice when the student returns to the text and reassesses it with fresh eyes. 
B. Peer feedback is known to be particularly useful especially for improving the structure and readability - the peer does not even have to be from the same field.

C. Writing checklists should be provided to university students to help them direct their focus to the most common mistakes.

Students need assistance in learning to help themselves and to correct their own and their peers' texts, which is why in the WDR course under scrutiny here, every class ended in a guided 30-minute review session, where every researcher analysed a peer's sample against a checklist. Taking a peek into the peer's mistakes, imitating their best practices, articulating your perception of their success, and being exposed to critique all constitute effective ways of raising awareness of common mistakes and of successful writing strategies.

\section{Polishing my style}

The second major challenge according to the student survey was style, including topics such as weak verbs, adverb position, colloquialisms, repetition, redundancy and phrasal verbs. The author's specific stylistic and organizational choices matter greatly as they support overall text usability but also the build-up of author credibility and content reliability by engineering reader perceptions (Hilton et al. 1989). Style is probably the most evident feature of academic writing as it materializes in so many aspects and levels of writing and visibly manifests the register or genre of the text.

The student sample supported the quantitative results, calling for guidance on academic style. Grammatically the texts were of high quality but featured strategies that, although common, lacked effect or precision:

Use of weak verbs:

e.g. "Hydrological processes and catchment characteristics are the key drivers for the diffuse nutrient loading from agricultural fields to surface waters."

Use of phrasal verbs:

e.g. "This article looks at the related feasibility problem."

\section{Expressing my views with precision}

One key feature in scientific writing is the ability to make solid arguments and to support the given claims with empirical evidence and theory instead of their own insights or intuitive opinions. In the survey, student concerns over preciseness signal their awareness of the criticality of accuracy as a trait of academic writing, especially in terms of argumentativity. Argumentation does not refer to the creation of new scientific information but only to the verification, grounding and justification of already existing ideas. It involves building logically binding conclusions on the premises (Hakkarainen 1999).

Precision and clarity of expression are particularly essential when critically reporting one's own empirical results but also when objectively reviewing other authors' studies while providing sufficient credit. Researchers sometimes fail to meet the requirements for objectivity and criticality and make observations that are unreliable, perhaps remembering inaccurately or selectively. Selectivity in scientific research can take many forms. In his or her attempts to establish a particular position or conclusion, the scientist may intuitively only cover material that supports the hypothesis and ignores sources that weaken or contradict the argument. Intellectual dishonesty may also surface as selective critique where the researcher covers the relevant material but applies more critical methodological standards to opposing evidence (Hakkarainen 1999 and Uusitalo 1997).

In addition to making accurate claims that hold, academic writing follows certain linguistic conventions that support argumentation, aiming to produce text that is effective, to the point, and weighs evidence objectively. Effectiveness means the text is devoid of redundancy yet adequately unambiguous. Being to the point sets requirements for terminology choices, be 
they key concepts or reporting verbs applied to comment on research findings. Evidencebased reasoning is unbiased and gives credit to the original sources of data, avoids farfetched generalizations, describes action (especially research aims) accurately and dynamically, and self-critically keeps in mind the limitations of the study.

Based on the text analysis, typical features manifesting lack of precision include:

Redundant elements (existential subject):

e.g. "To improve the present situation, there exists an immediate need for engineering the energy sector transitions in developing countries."

Triviality (self-evident claim with insufficient argumentation):

e.g. "Energy storage plays an essential role in the modern society."

While the message as such might seem pertinent for building topic relevance, it conveys the difficulty of establishing common ground with the reader while avoiding trivial statements. Pre-examiners at Aalto University often criticize openings like this for their unscientific and self-evident arguments.

\section{Mastering grammar}

In the European education system, language teaching has traditionally placed much emphasis on grammar and appropriate use of the language. As a result, students' language proficiency level is high but they are also overly cautious about making mistakes. Naturally, correct grammar is a concern in academic writing that aims at publication but possibly respondent biases stemming from educational emphases may have influenced the scores received for this question item. Also social desirability may encourage students to emphasize grammar in a survey that was responded to in a doctoral writing course. The author is therefore inclined to attribute some of this concern rather to the education culture than any severe handicaps in the area.

Indeed, the qualitative analysis of the student text sample indicates that generally the mastery of grammar poses no problems hindering text comprehensions, but there are some features that pose challenges universally, and they mostly stem from punctuation. In particular, relative clauses and the decision between restrictive or non-restrictive seem problematic, but some students also experience difficulties with premodifier hyphenation and article usage in connection with pre- or postmodified nouns. Some examples illustrating these challenges include:

punctuation:

e.g. "Some citizen science is also used in water quality monitoring which is in the focus of this paper."

hyphenation in compound premodification:

e.g. "Design can contribute specifically to the development of systems level solutions."

\section{Getting started with writing}

The theme of getting started with writing was introduced in the preliminary surveys, class discussions and found supporting evidence in the quantitative survey, but naturally no indication of writing inhibitions or procrastination can be detected in the text samples. Novice writers complained about writing anxiety more, whereas proficient writers claimed to be spending less time procrastinating and simply got ahead with the first draft and then later finetuned it into a finished piece. 
Quality is the end-product of laborious, countless revisions of originally sketchy and incomplete writing. Ambitious researchers who aim high with their substantive content have to learn to adjust their expectations and to accept redrafting as a natural part of the process. Mentally, the two key messages to be accentuated with any hesitant students are: 1) writers learn to write by writing, and 2) quality results from revision (Murray 2006). To help students skip the procrastination phase, they are provided with the CaRS (Create a Research Space) model as a roadmap for initial structuring (Swales and Feak 2012), and are advised to draw mindmaps, sketch their higher-level storyline, use bulleted wordlists to preliminarily document their main claims, and outline the article headings to lower the threshold of writing.

Most authors are familiar with the blank-page syndrome and therefore the writer's block should not be dramatized. Instead, researchers can develop writing techniques where one mechanically inserts passages of text, either full sentences or shorter phrases, to be further revised later. Once the text is published, the readers will not know in which order it was created. Only the reading has to be logical, not the writing. Putting something down on paper provides the author with a sense of achievement, which is a powerful motivator for further writing (Murray 2006).

\section{Additional topics identified through text analysis}

Additionally, four topics emerged from the analysis of the 74 student texts: inconsistent topicalization, ambiguous description of research aims, run-on expressions, and incorrect verbs describing causality or consequence.

\section{Topicalization}

Readers have expectations for organization, and even though students in the survey did not rate this particular dimension as extremely challenging, their texts revealed difficulty in placing familiar information before new information in their sentences. This given-before-new ordering adds flow and coherence and supports topic build-up. Effective topicalization helps avoid mechanistic listing of evidence and facilitates grouping of information into easily comprehensible blocks.

\section{Poorly progressing evidence ordering that corrupts cohesion:}

The incidence rate of inflammatory bowel disease (IBD) is increasing in industrialized countries worldwide. The identification of standard diagnosis criteria remains complicated as the cause of the disease remains unknown. Endoscopic methods such as ileoscopy are generally employed to determine the level of inflammation. To reduce the invasiveness, a computational classification system is required.

A possible solution placing familiar information upon sentence beginnings could look like this:

The incidence rate of inflammatory bowel disease (IBD) is increasing in industrialized countries worldwide. The cause of the disease remains unknown, which complicates identification of standard diagnosis criteria. The level of inflammation is generally determined by endoscopic methods such as ileoscopy which cannot be conducted on pediatric patients due to its invasiveness. To delineate the diagnosis and reduce the invasiveness, a computational classification system is required.

\section{Stating research aims}

Engineers typically describe their research aims by resorting to verbs such as focus on and study.

Obscure and unarticulated research aims:

e.g. "This paper focuses on describing the process for identifying service value and transferring this knowledge into concept design." 
However, the qualitative analysis showed that research in engineering typically falls within three main categories: 1) comprehending a phenomenon, 2) designing a solution, or 3) applying verified knowledge of a product or service in practice.

According to the category the overall research objective belongs to, the research aims could more accurately be described by means of the following verbs:

1) comprehension: analyse, compare, examine, investigate, define, determine, monitor, understand, experiment with

2) application: confirm, compare, corroborate, experiment with, evaluate, measure, monitor, prove, simulate, test, validate, verify

3) design: build, construct, develop, model, integrate

\section{Run-on expressions}

Engineers sometimes interrupt their flow by ending their claims in run-on expressions such as and so on and etc. This means typically that they offer their audience no superordinate nouns directing the reader's attention to the commonalities and content of the listed items.

Missing superordinate noun:

e.g. "Degradation in ageing can also be facilitated by the action of cobalt, manganese etc."

\section{Reporting causality or consequence in data commentary}

When reporting data and commenting either on their own findings or those of other researchers, engineering researchers often look for and address causality processes. However, the students in the sample lacked variety in expressing the connection or association between an original source phenomenon and its end outcomes, frequently resorting to the verb cause. A cause is something that induces, elicits or produces something else. Resultatively, a change in $x$ causes a change in $Y$. This reaction often requires certain conditions. The relationship between $X$ and $Y$ can be deterministic (X always causes $Y$ ) or probabilistic ( $X$ increases the probability of $Y$ ). Causalities are addressed frequently in engineering texts but if the process is not that solidly linear, the author could consider applying verbs such as contribute to, result in, result from, affect, influence, eventuate, elicit, induce or impact.

e.g. "The variation of the fuel moisture content significantly causes the furnace pressure and causes large disturbances to the pressure control loop."

Sometimes a separate verb describing the consequence is redundant, as in the following example:

e.g. "Peeling-off reactions cause shortening of cellulose chains." (shortens)

\section{Discussion}

This study has shown how prevalent institutional practices and pedagogy can be challenged to build research-informed education based more solidly on research evidence and authentic materials. Instead of continuing to provide poor or insufficient support, which is too often the experience of doctoral candidates, Aalto University has systematically and persistently begun to refine the doctoral research programs it houses. The ultimate aim is to build disciplinespecific support that would also speed up researcher socialization into their community of practice (Yu 1998). This calls for pedagogy that, instead of stoking student anxiety and inhibitions, provides instruments facilitating writing in the laborious path towards permanence and tenure. The doctoral student needs analysis reported here indicated that the needs are two-fold: on the one hand, the well-established problem of writing-related anxiety requires 
more attention, and on the other, writing itself could relatively easily be facilitated by responding to concrete needs involving conformity to academic standards, such as style and reporting conventions. On the doctoral level, the role of grammar also becomes accentuated when pursuing accurate, unambiguous and formal expression as well as author credibility.

As the amount of doctoral degrees attained annually constitutes one of the funding criteria for Finnish universities, considerable pressure is placed on doctoral candidates regarding their publication productivity and the time to completion. In the academic world, research itself, identification with the scholarly community and publications matter and are thereby central to the education system, too. The increased pressure for productivity and generation of publications easily drives academics to anxiety, especially as they often have to cope with multiple roles in their faculty. On this level, the system strongly counts on the candidates', super-learners', self-directedness and motivation, trusting their capability to learn and their initiative to study on their own. In the absence of faculty resources and the related challenges with teacher workloads, universities risk offering education that is insufficiently targeted, tailored or domain-specific. This study represented a modest effort to analyse and understand doctoral students' needs but due to the limited sample size, the findings should only be regarded as suggestive for pedagogic and policy-level development. 


\section{References}

Aitchison, C. and Mowbray, S. (2013) 'Doctoral Women: Managing Emotions, Managing Doctoral Studies'. Teaching in Higher Education 18(8), 859-870

Aitchison, C. and Lee, A. (2006) 'Research Writing: Problems and Pedagogies'. Teaching in Higher Education 11(3), 265-278

Allison, D., Cooley, L., Lewkowicz, J., and Nunan, D. (1998) ‘Dissertation Writing in Action: The Development of a Dissertation Writing Support Program for ESL Graduate Research Students'. English for Specific Purposes 17(2), 199-217

Borges, J., Galvao Dias, T., and Cunha, J. (2009) 'A New Group-Formation Method for Student Projects'. European Journal of Engineering Education, 34(6), 573-585

Brodie, L. and Porter, M. (2008) 'Engaging Distance and On-Campus Students in ProblemBased Learning'. European Journal of Engineering Education 33(4), 433-444

Caffarella, R. and Barnett, B. (2000) 'Teaching Doctoral Students to Become Scholarly Writers: The Importance of Giving and Receiving Critiques'. Studies in Higher Education 25(1), 39-52

Cagiltay, N. (2008) 'Using Learning Styles Theory in Engineering Education'. European Journal of Engineering Education 33(4), 415-424

Cassidy, S. (2012) 'Exploring Individual Differences as Determining Factors in Student Academic Achievement in Higher Education'. Studies in Higher Education 37(7), 793 $-810$

Charles, M., Pecorari, D., and Hunston, S. (2009) 'Introduction: Exploring the Interface between Corpus Linguistics and Discourse Analysis'. in Academic Writing. At the Interface of Corpus and Discourse. ed. by Charles, M., Pecorari, D., and Hunston, S. London and New York: Continuum, 1-13

Cotterall, S. (2011) 'Doctoral Students Writing: Where's the Pedagogy?'. Teaching in Higher Education 16(4), 413-425

Douglas, J. (2015) 'Developing an English for Academic Purposes Course for L2 Graduate Students in the Sciences'. Academic Writing: Interdisciplinary Perspectives on Communication Across the Curriculum, 12(3)

Goleman, D. (1998) Working with Emotional Intelligence. New York: Bantam Books

Hacker, D. (1999) A Writer's Reference. Boston: Bedford/St. Martin's

Hakkarainen, K., Lonka, K., and Lipponen, L. (1999) Tutkiva Oppiminen ['Explorative Learning']. Porvoo: WSOY

Halliday, M.A.K. (1994) An Introduction to Functional Grammar. London: Arnold.

Hilton, C., Motes, W., and Fielden, J. (1989) 'An Experimental Study of the Effects of Style and Organization on Reader Perceptions of Text'. Journal of Business Communication 26(3), 255-270

Huhta, M. (2010) Language and Communication for Professional Purposes - Needs Analysis Methods in Industry and Business and Their Yield to Stakeholders. Unpublished dissertation. Helsinki: Helsinki University of Technology 
Kamler, B. (2008) 'Rethinking Doctoral Publication Practices. Writing from and Beyond the Thesis'. Studies in Higher Education 33(3), 283-294

King, P., and Witt, P. (2009) 'Teacher Immediacy, Confidence Testing, and the Measurement of Cognitive Learning'. Communication Education 58(1), 110-123

Kreps, G., and Lederman, L. (1985) 'Using the Case Method in Organizational Communication Education: Developing Students' Insight, Knowledge, and Creativity Through Experience-Based Learning and Systematic Debriefing'. Communication Education 34(4), 358-364

Lappalainen, P. (2012). Socially Competent Leadership - Predictors, Impacts and Skilling in Engineering. Lappeenranta University of Technology. Dissertation Series, 347

Lee, A., and Kamler, B. (2008) 'Bringing Pedagogy to Doctoral Publishing'. Teaching in Higher Education 13(5), 511-523

Manathunga, C., Pittb, R., Cox, L., Boreham, P., Mellick, C., and Lant, P. (2012) 'Evaluating Industry-Based Doctoral Research Programs: Perspectives and Outcomes of Australian Cooperative Research Centre Graduates'. Studies in Higher Education 37(7), 843-858

McAlpine, L. and Amundsen, C. (2012) 'Challenging the Taken-for-Granted: How Research Analysis Might Inform Pedagogical Practices and Institutional Policies Related to Doctoral Education'. Studies in Higher Education 37(6), 683-694

McLeod, I., Steckley, L., and Murray, R. (2012) 'Time is Not Enough: Promoting Strategic Engagement with Writing for Publication'. Studies in Higher Education 37(6), 641-654

Murray, R. (2006) How to Write a Thesis. Maidenhead: Open University Press

Paltridge, B. (2009) 'Thesis and Dissertation Writing: Preparing ESL Students for Research'. English for Specific Purposes 16(1), 61-70

Paltridge, B., Starfield, S., Ravelli, R., and Nicholson, S. (2012) 'Doctoral Writing in the Visual and Performing Arts: Two Ends of a Continuum'. Studies in Higher Education 37(8), 989-1003

Stapp, Y. (1998) 'Instructor-Employer Collaboration: A Model for Technical Workplace English'. English for Specific Purposes 17(2), 169-182

Strauss, P. (2012) 'The English is Not the Same: Challenges in Thesis Writing for Second Language Speakers of English'. Teaching in Higher Education 17(3), 283-293

Swales, J., and Feak, C. (2012) Academic Writing for Graduate Students. $3^{\text {rd }}$ edn. Ann Arbor, MI: University of Michigan Press

Uusitalo, H. (1997) Tiede, Tutkimus ja Tutkielma. Johdatus Tutkielman Maailmaan ['Science, Research and Thesis']. Juva: WSOY

Yu, R. (1998) 'Non-Native Graduate Students' Thesis/Dissertation Writing in Science: SelfReports by Students and their Advisors from Two U.S. Institutions'. English for Specific Purposes 17(4), 369-390 